$$
\text { Review Article }
$$

Seminars in Medicine of the

Beth Israel Deaconess Medical Center

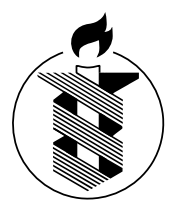

Jeffrey S. Flier, M.D., Editor

Lisa H. Underhill, Assistant Editor

\section{Protective and Damaging Effects of STREsS Mediators}

\author{
BRuce S. McEWEN, PH.D.
}

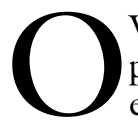

VER 60 years ago, Selye ${ }^{1}$ recognized the paradox that the physiologic systems activated by stress can not only protect and restore but also damage the body. What links these seemingly contradictory roles? How does stress influence the pathogenesis of disease, and what accounts for the variation in vulnerability to stress-related diseases among people with similar life experiences? How can stress-induced damage be quantified? These and many other questions still challenge investigators.

This article reviews the long-term effect of the physiologic response to stress, which I refer to as allostatic load. ${ }^{2}$ Allostasis - the ability to achieve stability through change ${ }^{3}-$ is critical to survival. Through allostasis, the autonomic nervous system, the hypothalamic-pituitary-adrenal (HPA) axis, and the cardiovascular, metabolic, and immune systems protect the body by responding to internal and external stress. The price of this accommodation to stress can be allostatic load, ${ }^{2}$ which is the wear and tear that results from chronic overactivity or underactivity of allostatic systems.

From the Harold and Margaret Milliken Hatch Laboratory of Neuroendocrinology, Box 165, Rockefeller University, 1230 York Ave., New York, NY 10021, where reprint requests should be addressed to Dr. McEwen.

(C) 1998, Massachusetts Medical Society.

\section{THE PHYSIOLOGIC RESPONSE TO STRESS}

Stressful experiences include major life events, trauma, and abuse and are sometimes related to the environment in the home, workplace, or neighborhood. Acute stress (in the sense of "fight or flight" or major life events) and chronic stress (the cumulative load of minor, day-to-day stresses) can both have long-term consequences. The effects of chronic stress may be exacerbated by a rich diet and the use of tobacco and alcohol and reduced by moderate exercise.

Genetic factors do not account for all the individual variability in sensitivity to stress, as evinced by the lack of concordance between identical twins in many disorders. ${ }^{4,5}$ Moreover, genetic factors do not explain the gradients of health across socioeconomic levels in Western societies. ${ }^{6}$ Two factors largely determine individual responses to potentially stressful situations: the way a person perceives a situation ${ }^{7}$ and a person's general state of physical health, which is determined not only by genetic factors but also by behavioral and lifestyle choices (Fig. 1). Whether one perceives a situation as a threat, either psychological or physical, is crucial in determining the behavioral response - whether it is fleeing, fighting, or cowering in fear - and the physiologic response - calmness or heart palpitations and elevated cortisol levels.

The ability to adjust or habituate to repeated stress is also determined by the way one perceives a situation. For example, most people react initially to the challenge of public speaking with activation of the HPA axis. After repeated public speaking, however, most people become habituated and their cortisol secretion no longer increases with the challenge. But approximately 10 percent of subjects continue to find public speaking stressful, and their cortisol secretion increases each time they speak in public. ${ }^{8}$ Others are prone to a cardiovascular stress response, as shown by a recent study of cardiovascular responses to a stressful arithmetic test. Bloodpressure responses to this experimental stress predicted elevated ambulatory blood pressure during periods of perceived stress in everyday life. ${ }^{9}$ Genetics may also have a role in susceptibility to cardiovascular stress; many people whose blood pressure remains elevated for several hours after the stress of an arithmetic test have a parent with hypertension. ${ }^{10}$

One's physical condition has obvious implications for one's ability to mount an appropriate physiologic response to stressful stimuli, and there may be a genetic component to the response as well. In inbred 


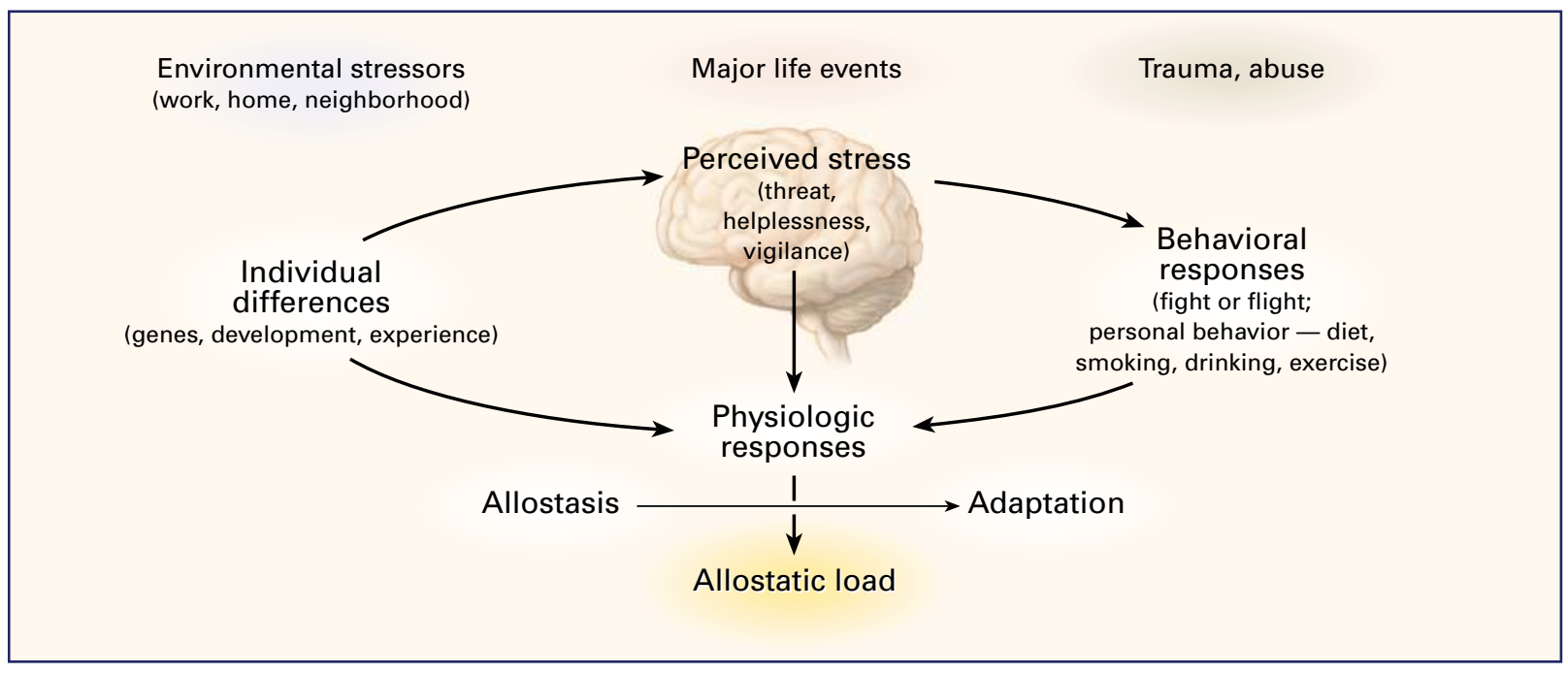

Figure 1. The Stress Response and Development of Allostatic Load.

The perception of stress is influenced by one's experiences, genetics, and behavior. When the brain perceives an experience as stressful, physiologic and behavioral responses are initiated, leading to allostasis and adaptation. Over time, allostatic load can accumulate, and the overexposure to mediators of neural, endocrine, and immune stress can have adverse effects on various organ systems, leading to disease.

BioBreeding (BB) rats, an animal model of insulindependent diabetes, exposure to repeated stress increased the incidence of diabetes. ${ }^{11}$ In children, family instability increases the incidence and severity of insulin-dependent diabetes. ${ }^{12}$ Chronic stress, defined as feelings of fatigue, lack of energy, irritability, demoralization, and hostility, has been linked to the development of insulin resistance, ${ }^{13}$ a risk factor for non-insulin-dependent diabetes. Deposition of abdominal fat, a risk factor for coronary heart disease and diabetes, ${ }^{14}$ is increased by the psychosocial stress of colony reorganization in nonhuman primates ${ }^{15}$ and may also be increased by stress in humans. ${ }^{16}$

\section{ALLOSTASIS AND ALLOSTATIC LOAD}

In contrast to homeostatic systems such as blood oxygen, blood $\mathrm{pH}$, and body temperature, which must be maintained within narrow ranges, allostatic (adaptive) systems have much broader boundaries. Allostatic systems enable us to respond to our physical states (e.g., awake, asleep, supine, standing, exercising) and to cope with noise, crowding, isolation, hunger, extremes of temperature, danger, and microbial or parasitic infection.

The core of the body's response to a challenge whether it is a dangerous situation, an infection, living in a crowded and unpleasant neighborhood, or a public-speaking test - is twofold, turning on an allostatic response that initiates a complex adaptive pathway, and then shutting off this response when the threat is past. The most common allostatic responses involve the sympathetic nervous systems and the HPA axis. For these systems, activation releases catecholamines from nerves and the adrenal medulla and leads to the secretion of corticotropin from the pituitary. The corticotropin, in turn, mediates the release of cortisol from the adrenal cortex. Figure 2 shows how catecholamines and glucocorticoids affect cellular events. Inactivation returns the systems to base-line levels of cortisol and catecholamine secretion, which normally happens when the danger is past, the infection is contained, the living environment is improved, or the speech has been given. However, if the inactivation is inefficient (see below), there is overexposure to stress hormones. Over weeks, months, or years, exposure to increased secretion of stress hormones can result in allostatic load ${ }^{2}$ and its pathophysiologic consequences.

Four situations are associated with allostatic load (Fig. 3). The first and most obvious is frequent stress. For example, surges in blood pressure can trigger myocardial infarction in susceptible persons, ${ }^{17}$ and in primates repeated elevations of blood pressure over periods of weeks and months accelerate atherosclerosis, ${ }^{18}$ thereby increasing the risk of myocardial infarction.

In the second type of allostatic load (Fig. 3), adaptation to repeated stressors of the same type is lacking, resulting in prolonged exposure to stress hormones, as was the case for some of the people subjected to the repeated-public-speaking challenge. ${ }^{8}$

In the third type of allostatic load (Fig. 3) there is an inability to shut off allostatic responses after a stress is terminated. As we have noted, the blood 


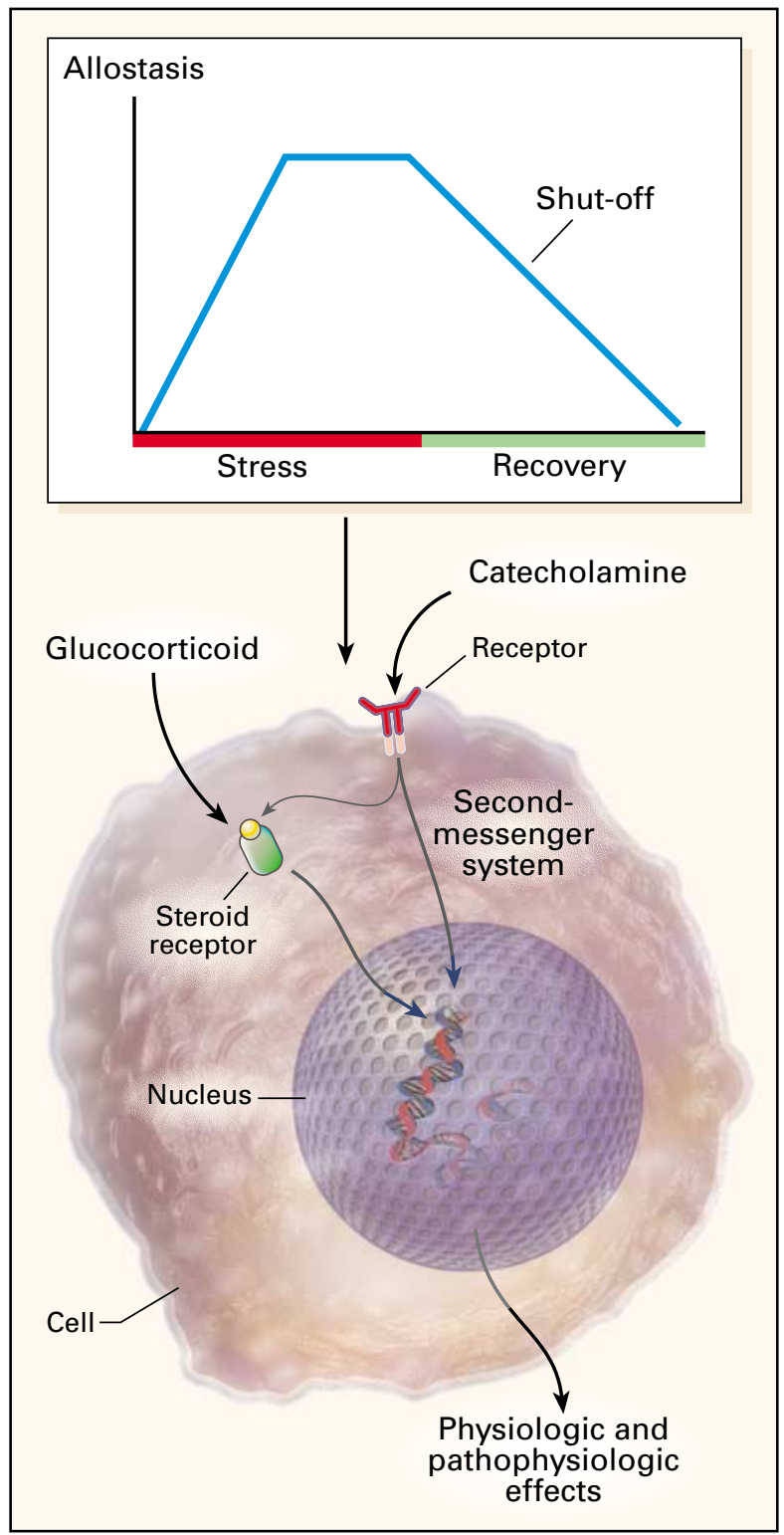

Figure 2. Allostasis in the Autonomic Nervous System and the HPA Axis.

Allostatic systems respond to stress (upper panel) by initiating the adaptive response, sustaining it until the stress ceases, and then shutting it off (recovery). Allostatic responses are initiated (lower panel) by an increase in circulating catecholamines from the autonomic nervous system and glucocorticoids from the adrenal cortex. This sets into motion adaptive processes that alter the structure and function of a variety of cells and tissues. These processes are initiated through intracellular receptors for steroid hormones, plasma-membrane receptors, and second-messenger systems for catecholamines. Cross-talk between catecholamines and glucocorticoid-receptor signaling systems can occur. pressure in some people fails to recover after the acute stress of an arithmetic test, ${ }^{10}$ and hypertension accelerates atherosclerosis. ${ }^{18}$ Women with a history of depressive illness have decreased bone mineral density, because the allostatic load of chronic, moderately elevated serum cortisol concentrations inhibits bone formation. ${ }^{19}$ Intense athletic training also induces allostatic load in the form of elevated sympathetic and HPA-axis activity, which results in weight loss, amenorrhea, and the often-related condition of anorexia nervosa. ${ }^{20,21}$

The failure to turn off the HPA axis and sympathetic activity efficiently after stress is a feature of agerelated functional decline in laboratory animals, $22-24$ but the evidence of this in humans is limited.25,26 Stress-induced secretion of cortisol and catecholamines returns to base line more slowly in some aging animals with other signs of accelerated aging, ${ }^{22-24}$ and the negative-feedback effects of cortisol are reduced in elderly humans. ${ }^{26}$ One other sign of age-related impairment in rats is that the hippocampus fails to turn off the release of excitatory amino acids after stress, ${ }^{27}$ and this may accelerate progressive structural damage and functional impairment (see below).

One speculation is that allostatic load over a lifetime may cause the allostatic systems to wear out or become exhausted. ${ }^{25} \mathrm{~A}$ vulnerable link in the regulation of the HPA axis and cognition is the hippocampal region. According to the "glucocorticoidcascade hypothesis," wear and tear on this region of the brain leads to dysregulation of the HPA axis and cognitive impairment. ${ }^{23,28}$ Indeed, some but not all aging rats have impairment of episodic, declarative, and spatial memory and hyperactivity of the HPA axis, all of which can be traced to hippocampal damage. ${ }^{29}$ Recent data suggest that similar events may occur in humans. ${ }^{30,31}$

In the fourth type of allostatic load (Fig. 3), inadequate responses by some allostatic systems trigger compensatory increases in others. When one system does not respond adequately to a stressful stimulus, the activity of other systems increases, because the underactive system is not providing the usual counterregulation. For example, if cortisol secretion does not increase in response to stress, secretion of inflammatory cytokines (which are counterregulated by cortisol) increases. ${ }^{32}$ The negative consequences of an enhanced inflammatory response are seen, for example, in Lewis rats; these animals are very susceptible to autoimmune and inflammatory disturbances, because of a genetically determined hyporesponsiveness of the HPA axis. ${ }^{33}$

In another model, rats that become subordinate in a psychosocial living situation called the "visibleburrow system" have a stress-induced state of HPA hyporesponsiveness. ${ }^{34,35}$ In these rats, the response to stressors applied by the experimenter is very limited, and concentrations of corticotropin-releasing 

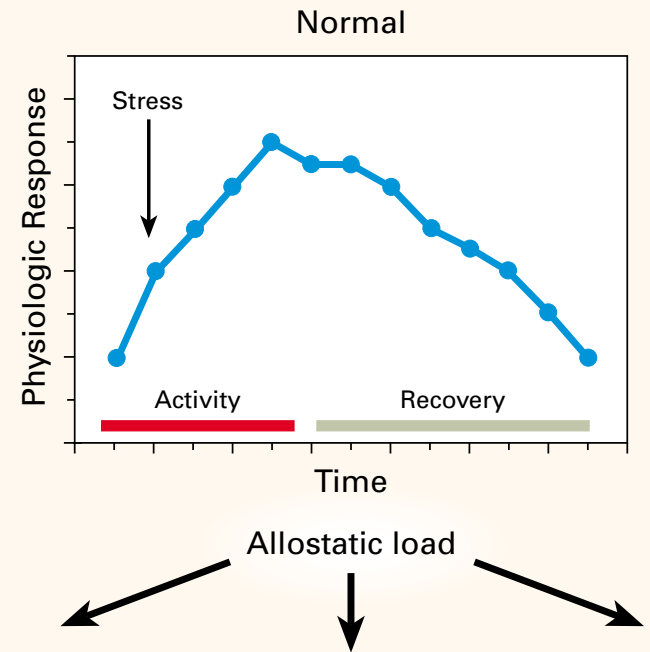

Repeated “hits"

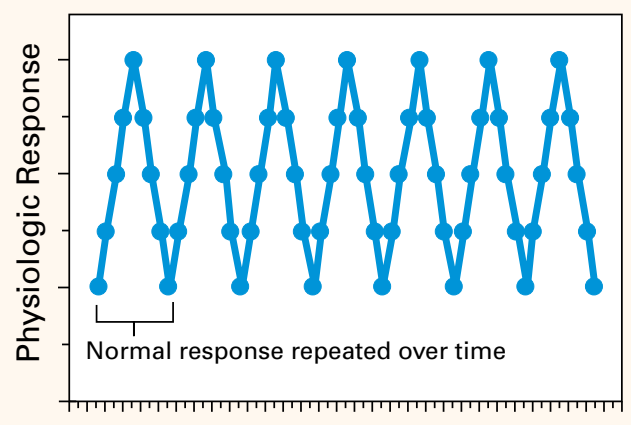

Time

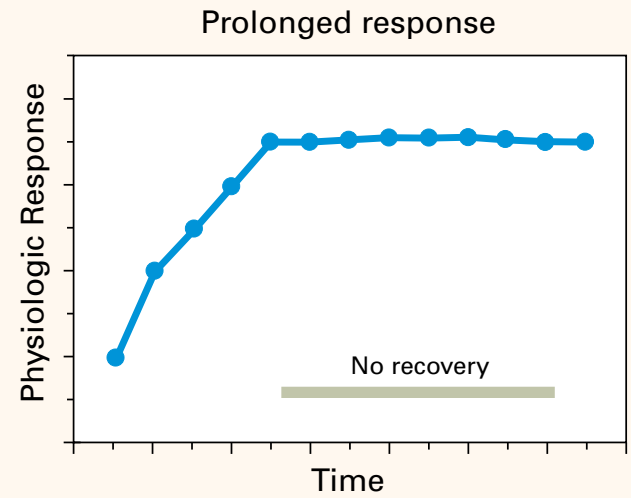

Lack of adaptation

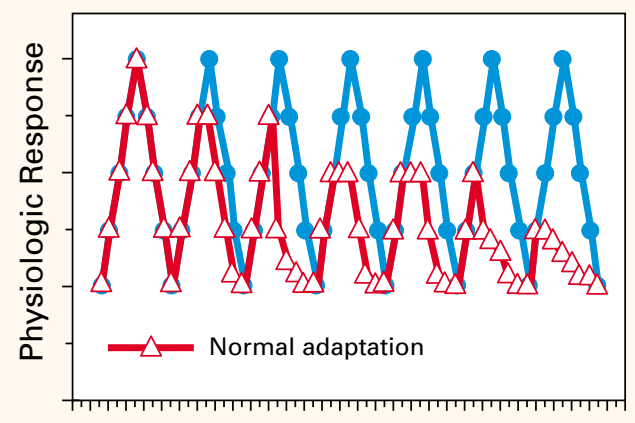

Time

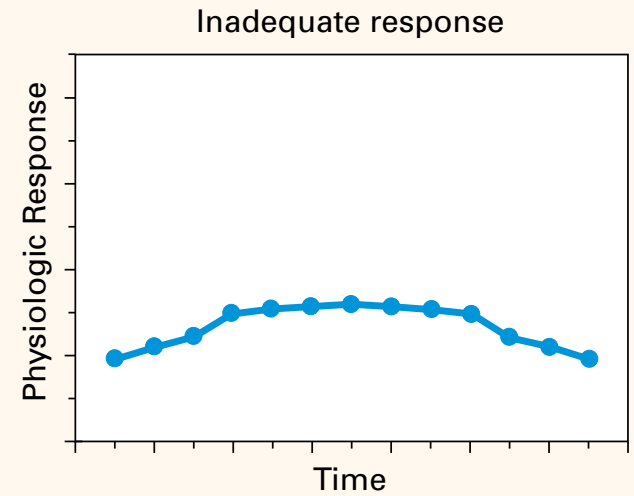

Figure 3. Three Types of Allostatic Load.

The top panel illustrates the normal allostatic response, in which a response is initiated by a stressor, sustained for an appropriate interval, and then turned off. The remaining panels illustrate four conditions that lead to allostatic load: repeated "hits" from multiple stressors; lack of adaptation; prolonged response due to delayed shutdown; and inadequate response that leads to compensatory hyperactivity of other mediators (e.g., inadequate secretion of glucocorticoids, resulting in increased concentrations of cytokines that are normally counterregulated by glucocorticoids). 
hormone messenger RNA in the hypothalamus are abnormally low. ${ }^{36}$ Human counterparts with HPA hyporesponsiveness include adults with fibromyalgia $^{37,38}$ and chronic fatigue syndrome ${ }^{39,40}$ and children with atopic dermatitis. ${ }^{41}$ In post-traumatic stress disorder, basal HPA activity is also low, ${ }^{42,43}$ although reactivity to stress may not be blunted.

Feelings of anticipation and worry can also contribute to allostatic load. ${ }^{44}$ Anticipation participates in the reflex that prevents us from blacking out when we get out of bed in the morning ${ }^{3}$ and is also part of worry, anxiety, and cognitive preparation for a threat. Anticipatory anxiety can drive the secretion of mediators like corticotropin, cortisol, and epinephrine, and for this reason, prolonged anxiety and anticipation are likely to result in allostatic load. ${ }^{44}$ For example, salivary cortisol concentrations increase within 30 minutes after waking in people who are under considerable psychological stress due to work or family matters. ${ }^{45}$ In a related fashion, intrusive memories of a traumatic event (as in post-traumatic stress disorder) can produce a form of chronic stress and can drive physiologic responses. ${ }^{46}$

Allostasis and allostatic load are also affected by the consumption of tobacco and alcohol, dietary choices, and the amount of exercise (Fig. 1). These forms of behavior are integral to the overall notion of allostasis - the way people cope with a challenge - and also contribute to allostatic load by known pathways (e.g., a high-fat diet accelerates atherosclerosis and progression to non-insulin-dependent diabetes by increasing cortisol secretion, leading to fat deposition and insulin resistance ${ }^{47}$; smoking elevates blood pressure and accelerates atherogenesis ${ }^{48}$; and exercise protects against cardiovascular disease ${ }^{49}$ ).

\section{EXAMPLES OF ALLOSTATIC LOAD}

\section{Cardiovascular and Metabolic Systems}

The best-studied system of allostasis and allostatic load is the cardiovascular system and its links to obesity and hypertension. In nonhuman primates, the incidence of atherosclerosis is increased among the dominant males of unstable social hierarchies and in socially subordinate females. ${ }^{50,51}$ In humans, lack of control on the job increases the risk of coronary heart disease, ${ }^{52}$ and job strain (high psychological demands and lack of control) results in elevated ambulatory blood pressure at home and an increased left-ventricular-mass index, ${ }^{53}$ as well as increased progression of atherosclerosis. ${ }^{54}$ Chronic stress (feelings of fatigue, lack of energy, irritability, and demoralization) and hostility are linked to increased reactivity of the fibrinogen system and of platelets, both of which increase the risk of myocardial infarction. ${ }^{55,56}$

Quantifying allostatic load, a major challenge, has been attempted with the use of measures of meta- bolic and cardiovascular pathophysiology. In a recent analysis, ${ }^{57}$ data from the MacArthur Studies of Successful Aging were used to assess eight measures of increased activity of allostatic systems between 1988 and 1991. Allostatic load was approximated by determining the number of measures for which a person had values in the highest quartile from among the following: systolic blood pressure, overnight urinary cortisol and catecholamine excretion, the ratio of the waist to the hip measurement, the glycosylated hemoglobin value, and the ratio of serum high-density lipoprotein in the total serum cholesterol concentration; and the number of the following for which the person had values in the lowest quartile: serum concentration of dehydroepiandrosterone sulfate and serum concentration of high-density lipoprotein cholesterol. In cross-sectional analyses of base-line data, subjects with higher levels of physical and mental functioning had lower allostaticload scores and a lower incidence of cardiovascular disease, hypertension, and diabetes. During the three years of follow-up (1988 to 1991), people in this higher-functioning group with higher allostatic-load scores at base line were more likely to have incident cardiovascular disease and were significantly more likely to have declines in cognitive and physical functioning. Among women in this group, increased cortisol secretion predicted a decline in memory. ${ }^{31}$

\section{The Brain}

Repeated stress affects brain function, especially in the hippocampus, which has high concentrations of cortisol receptors. ${ }^{58}$ The hippocampus participates in verbal memory and is particularly important for the memory of "context," the time and place of events that have a strong emotional bias. 59,60 Moreover, glucocorticoids are involved in remembering the context in which an emotionally laden event took place. ${ }^{61}$ Impairment of the hippocampus decreases the reliability and accuracy of contextual memories. This may exacerbate stress by preventing access to the information needed to decide that a situation is not a threat. ${ }^{62}$ The hippocampus also regulates the stress response and acts to inhibit the response of the HPA axis to stress. ${ }^{63,64}$

The mechanism for stress-induced hippocampal dysfunction and memory impairment is twofold. First, acute stress increases cortisol secretion, which suppresses the mechanisms in the hippocampus and temporal lobe that subserve short-term memory. ${ }^{65,66}$ Stress can impair memory in the short term, but fortunately these effects are reversible and relatively short-lived. ${ }^{67}$ Second, repeated stress causes the atrophy of dendrites of pyramidal neurons in the CA3 region of the hippocampus through a mechanism involving both glucocorticoids and excitatory amino acid neurotransmitters released during and after stress. ${ }^{68}$ This atrophy is reversible if the stress is short- 
lived, but stress lasting many months or years can kill hippocampal neurons. ${ }^{23,69}$ Magnetic resonance imaging has shown that stress-related disorders such as recurrent depressive illness, post-traumatic stress disorder, and Cushing's disease are associated with atrophy of the hippocampus. ${ }^{70,71}$ Whether this atrophy is reversible or permanent is not clear.

Long-term stress also accelerates the appearance of several biologic markers of aging in rats, including the loss of hippocampal pyramidal neurons and the excitability of pyramidal neurons in the CAl region by a calcium-dependent mechanism. ${ }^{72}$ Glucocorticoids may mediate these effects by enhancing calcium currents in the hippocampus, ${ }^{73}$ since calcium ions have a key role in destructive as well as plastic processes in hippocampal neurons. ${ }^{74-76}$ The persistent release of the excitatory amino acid glutamate in the hippocampus after stress in aged rats may also contribute to age-related neuronal damage ${ }^{27}$ and may potentiate atrophy and possibly even neuronal loss.

Early stress and neonatal handling influence the course of aging and age-related cognitive impairment in animals. Early experiences are believed to set the level of responsiveness of the HPA axis and autonomic nervous system. These systems overreact in animals subjected to early unpredictable stress and underreact in animals exposed to neonatal handling. ${ }^{77}$ In the former condition, aging of the brain is accelerated, whereas in the latter, aging of the brain is reduced. ${ }^{29,77}$

\section{The Immune System}

The immune system responds to pathogens or other antigens with its own form of allostasis that may include an acute-phase response as well as the formation of an immunologic "memory." At the same time, other allostatic systems, such as the HPA axis and the autonomic nervous system, tend to contain acute-phase responses and dampen cellular immunity. ${ }^{78}$ However, not all the effects are suppressive. Acute stress causes lymphocytes and macrophages to be redistributed throughout the body and to "marginate" on blood-vessel walls and within certain compartments, such as the skin, lymph nodes, and bone marrow. This "trafficking" is mediated in part by glucocorticoids. ${ }^{78-82}$ If an immune challenge is not encountered and the hormonal-stress signal ceases, immune cells return to the bloodstream. When a challenge occurs, however, as is the case in delayedtype hypersensitivity, acute stress enhances the traffic of lymphocytes and macrophages to the site of acute challenge. ${ }^{83,84}$

The immune-enhancing effects of acute stress depend on adrenal secretion and last for three to five days. Acute stress has the effect of calling immune cells to their battle stations, and this form of allostasis enhances responses for which there is an established immunologic "memory." $83-85$ If the immuno- logic memory is of a pathogen or a tumor cell, the result of stress is presumably beneficial. If, on the contrary, the immunologic memory leads to an autoimmune or allergic response, then stress is likely to exacerbate a pathologic state. When allostatic load is increased by repeated stress, the outcome is completely different; the delayed hypersensitivity response is substantially inhibited ${ }^{86}$ rather than enhanced. The consequences of suppressed cellular immunity resulting from chronic stress include increased severity of the common cold, accompanied by increased titers of cold-virus antibody. ${ }^{87}$ In laboratory animals, repeated stress also leads to recurrent endotoxemia, which decreases the reactivity of the HPA axis to a variety of stimuli and decreases production of the cytokine tumor necrosis factor $\alpha .^{88}$

\section{Implications of Allostatic Load in Human Society}

The gradients of health across the range of socioeconomic levels 6 relate to a complex array of risk factors that are differentially distributed in human society. ${ }^{89,90}$ Perhaps the best example is offered by the Whitehall studies of the British civil service, in which mortality and morbidity were found to increase stepwise from the lowest to the highest of the six grades of the British civil service. ${ }^{91}$ Hypertension was a sensitive index of job stress, ${ }^{92}$ particularly among factory workers, other workers with repetitive jobs and time pressures, ${ }^{93}$ and workers whose jobs were unstable because of departmental privatization (Marmot MG: personal communication). Plasma fibrinogen concentrations, which predict an increased risk of death from coronary heart disease, are elevated among men in the lower British civil-service grades. ${ }^{56}$ In less stable societies, conflict and social instability have been found to accelerate pathophysiologic processes and increase morbidity and mortality. For example, cardiovascular disease is a major contributor to the increase of almost 40 percent in the death rate among Russian men during the social collapse that followed the fall of Communism. ${ }^{94}$ Blood-pressure surges and sustained elevation are linked to accelerated atherosclerosis ${ }^{18}$ as well as to an increased risk of myocardial infarction. ${ }^{17}$

Another stress-linked change is abdominal obesity (see above), measured as an increased waist-to-hip ratio. The waist-to-hip ratio is increased at the lower end of the socioeconomic-status gradient in Swedish men $^{95}$ and in the lower civil-service grades in the Whitehall studies. ${ }^{96}$ Immune-system function is also a likely target of psychosocial stress, ${ }^{97}$ increasing vulnerability to such infections as the common cold..$^{87,98}$

\section{Therapeutic Implications}

A consideration of allostatic load is increasingly important in the diagnosis and treatment of many illnesses. Allostatic load is also important in illuminating the relation between disease and social insta- 
bility, job loss, dangerous living environments, and other conditions that are chronically stressful. Medical illness itself is a source of stress, producing anxiety about prognosis, treatment, disability, and interference with social roles and relationships.

Physicians and other health care providers can help patients reduce allostatic load by helping them learn coping skills, recognize their own limitations, and relax. Patients should also be reminded of the interactions of a high-fat diet and stress in atherosclerosis, the role of smoking in cardiovascular disease and cancer, and the beneficial effects of exercise. But the patients themselves must change their behavior patterns appropriately.99,100

Beyond these obvious steps, other types of interventions must be considered. Two important causes of allostatic load appear to be isolation ${ }^{101}$ and lack of control in the work environment. ${ }^{52}$ Interventions that increase social support and enhance coping prolong the life spans of patients with breast cancer, ${ }^{102}$ lymphomas, ${ }^{103}$ and malignant melanoma. ${ }^{104}$ Interventions designed to increase a worker's control over his or her job, such as the reorganization of auto production at Volvo, have also improved health and attitudes toward work. ${ }^{93}$

\section{DISCUSSION}

DR. JEFFREY FLIER: Is there any known correlation between lifelong stress (and therefore allostatic load) and Alzheimer's disease?

Dr. McEwEn: There are a few anecdotes from admissions personnel at Veterans Affairs hospitals but nothing concrete. It is interesting, however, that education appears to have a "protective" role against the development of Alzheimer's disease. ${ }^{105}$ It is not clear, though, whether education protects against the disease or provides more redundancy in the brain, which delays the symptoms. ${ }^{106}$

DR. BARBARA B. KAHN: What are the important differences between men and women in the biology of stress?

Dr. McEwen: Estrogens appear to protect the cardiovascular system, and at menopause, women's risk of cardiovascular disease increases to that of agematched men. The decline in estrogen secretion at menopause also increases the activity of the HPA axis, ${ }^{107}$ a development that has been linked to greater cognitive decline among elderly women than among elderly men. ${ }^{31} \mathrm{~A}$ decline in androgen secretion in older men may affect HPA function, although to a lesser extent. In rats, castration increases HPA activity. ${ }^{108}$ Finally, there are structural and functional differences between the sexes in hippocampal formation in rodents, ${ }^{109-111}$ and behavioral evidence suggests functional and possibly structural sex differences in humans, as well. ${ }^{112}$ We do not yet know whether these differences influence the vulnerability of the hippocampus to severe stress, although a number of studies now suggest that female rodents and primates may be less vulnerable than males. ${ }^{69,113}$

DR. FLIER: Is there any evidence that humans are more susceptible to the effects of stress than animals because of the greater human capacity for cognition and insight, as well as the human ability to feel guilt?

DR. MCEwEN: I believe that humans are more at risk for allostatic load than animals, because of the enormous individual differences in stress responsiveness and aging among humans, which relate to life experiences, personality, and physiologic phenotype. However, stress responsiveness and aging also differ among rats, so I don't think we can be definitive about the importance of cognition in our own species.

A PHysician: What mechanisms underlie the differences between immune responses to acute stress and those to chronic stress?

DR. McEwen: These mechanisms are just beginning to be understood. One key process is the redistribution, or trafficking, of immune cells. Acute stress enhances this response to delayed-type hypersensitivity. Chronic stress impairs delayed-type hypersensitivity, with the result that the blood is depleted of fewer lymphocytes. The greater the impairment of delayed-type hypersensitivity, the less the blood is depleted of lymphocytes (Dhabhar FS: unpublished data). Glucocorticoids are responsible for the trafficking of lymphocytes and for the stress enhancement of delayed-type hypersensitivity, but they do not act alone. Various cytokines function as more-local signals, emanating from a site of infection or challenge, and Dr. Firdaus Dhabhar at Rockefeller University is investigating their involvement. Beyond that, it is well known that stress hormones modulate immune function and influence the class of the immune response by their ability to increase the expression of some cytokines and decrease the expression of others. ${ }^{78}$

I am indebted to the Health Program of the John D. and Catherine T. MacArthur Foundation and its Network on Socioeconomic Status and Health for contributions to the concepts discussed in this article, and to Dr. Firdaus Dhabhar for assistance with Figure 3.

\section{REFERENCES}

1. Selye H. Syndrome produced by diverse nocuous agents. Nature 1936; $138: 32$

2. McEwen BS, Stellar E. Stress and the individual: mechanisms leading to disease. Arch Intern Med 1993;153:2093-101.

3. Sterling P, Eyer J. Allostasis: a new paradigm to explain arousal pathology. In: Fisher S, Reason J, eds. Handbook of life stress, cognition and health. New York: John Wiley, 1988:629-49.

4. Berg K. Genetics of coronary heart disease. Prog Med Genet 1983;5: 35-90.

5. Plomin R. The role of inheritance in behavior. Science 1990;248:183-8. 6. Adler NE, Boyce T, Chesney MA, et al. Socioeconomic status and health: the challenge of the gradient. Am Psychol 1994;49:15-24

7. Lazarus RS, Folkman S. Stress, appraisal and coping. New York: Spring er-Verlag, 1984.

8. Kirschbaum C, Prussner JC, Stone AA, et al. Persistent high cortisol re- 
sponses to repeated psychological stress in a subpopulation of healthy men Psychosom Med 1995;57:468-74.

9. Matthews KA, Owens JF, Allen MT, Stoney CM. Do cardiovascular responses to laboratory stress relate to ambulatory blood pressure levels? Yes, in some of the people, some of the time. Psychosom Med 1992;54:68697.

10. Gerin W, Pickering TG. Association between delayed recovery of blood pressure after acute mental stress and parental history of hypertension. J Hypertens 1995;13:603-10.

11. Lehman $C$, Rodin $J$, McEwen BS, Brinton R. Impact of environmental stress on the expression of insulin-dependent diabetes mellitus. Behav Neurosci 1991;105:241-5.

12. Hagglof B, Blom L, Dahlquist G, Lonnberg G, Sahlin B. The Swedish childhood diabetes study: indications of severe psychological stress as a risk factor for type 1 (insulin-dependent) diabetes mellitus in childhood. Diabetologia 1991;34:579-83

13. Raikkonen K, Keltikangas-Jarvinen L, Adlercreutz H, Hautenen A. Psychosocial stress and the insulin resistance syndrome. Metabolism 1996; 45:1533-8.

14. Bjorntorp P. "Portal" adipose tissue as a generator of risk factors for cardiovascular disease and diabetes. Arteriosclerosis 1990;10:493-6.

15. Jayo JM, Shively CA, Kaplan JR, Manuck SB. Effects of exercise and stress on body fat distribution in male cynomolgus monkeys. Int J Obes Relat Metab Disord 1993;17:597-604.

16. Mover AE, Rodin J, Grilo CM, Cummings N, Larson LM, RebuffeScrive M. Stress-induced cortisol response and fat distribution in women. Obes Res 1994;2:255-61.

17. Muller JE, Tofler GH, Stone PH. Circadian variation and triggers of onset of acute cardiovascular disease. Circulation 1989;79:733-43.

18. Kaplan JR, Pettersson K, Manuck SB, Olsson G. Role of sympathoadrenal medullary activation in the initiation and progression of atherosclerosis. Circulation 1991;84:Suppl VI:VI-23-VI-32.

19. Michelson D, Stratakis C, Hill L, et al. Bone mineral density in women with depression. N Engl J Med 1996;335:1176-81.

20. Boyar RM, Hellman LD, Roffwarg $\mathrm{H}$, et al. Cortisol secretion and metabolism in anorexia nervosa. N Engl J Med 1977;296:190-3.

21. Loucks AB, Mortola JF, Girton L, Yen SSC. Alterations in the hypothalamic-pituitary-ovarian and the hypothalamic-pituitary-adrenal axes in athletic women. J Clin Endocrinol Metab 1989;68:402-11.

22. McCarty R. Sympathetic-adrenal medullary and cardiovascular responses to acute cold stress in adult and aged rats. J Auton Nerv Syst 1985; 12:15-22.

23. Sapolsky RM. Stress, the aging brain and the mechanisms of neuron death. Cambridge, Mass.: MIT Press, 1992.

24. McEwen BS. Re-examination of the glucocorticoid hypothesis of stress and aging. In: Swaab DF, Hofman MA, Mirmiran M, Ravid R, van Leeuwen FW, eds. Progress in brain research. Vol. 93. The human hypothalamus in health and disease. Amsterdam: Elsevier Science, 1992:365-83. 25. Seeman TE, Robbins RJ. Aging and hypothalamic-pituitary-adrenal response to challenge in humans. Endocr Rev 1994;15:233-60.

26. Wilkinson CW, Peskind ER, Raskind MA. Decreased hypothalamicpituitary-adrenal axis sensitivity to cortisol feedback inhibition in human aging. Neuroendocrinology 1997;65:79-90.

27. Lowy MT, Wittenberg L, Yamamoto BK. Effect of acute stress on hippocampal glutamate levels and spectrin proteolysis in young and aged rats. J Neurochem 1995;65:268-74.

28. Sapolsky RM, Krey LC, McEwen BS. The neuroendocrinology of stress and aging: the glucocorticoid cascade hypothesis. Endocr Rev 1986; 7:284-301.

29. Meaney MJ, Aitken DH, van Berkel C, Bhatnagar S, Sapolsky RM. Effect of neonatal handling of age-related impairments associated with the hippocampus. Science 1988;239:766-8.

30. Lupien S, Lecours AR, Lussier I, Schwartz G, Nair NPV, Meaney MJ Basal cortisol levels and cognitive deficits in human aging. J Neurosci 1994;14:2893-903.

31. Seeman TE, McEwen BS, Singer BH, Albert MS, Rowe JW. Increase in urinary cortisol excretion and memory declines: MacArthur studies of successful aging. J Clin Endocrinol Metab 1997;82:2458-65.

32. Munck A, Guyre PM, Holbrook NJ. Physiological functions of glucocorticoids in stress and their relation to pharmacological actions. Endocr Rev 1984;5:25-44.

33. Sternberg EM, Young WS III, Bernardini R, et al. A central nervous system defect in biosynthesis of corticotropin-releasing hormone is associated with susceptibility to streptococcal cell wall-induced arthritis in Lewis rats. Proc Natl Acad Sci U S A 1989;86:4771-5.

34. Blanchard DC, Sakai RR, McEwen BS, Weiss SM, Blanchard RJ. Subordination stress: behavioral, brain, and neuroendocrine correlates. Behav Brain Res 1993;58:113-21.

35. McKittrick CR, Blanchard DC, Blanchard RJ, McEwen BS, Sakai RR.
Serotonin receptor binding in a colony model of chronic social stress. Biol Psychiatry 1995;37:383-93.

36. Albeck DS, McKittrick CR, Blanchard DC, et al. Chronic social stress alters expression of corticotropin-releasing factor and arginine vasopressin mRNA in rat brain. J Neurosci 1997;17:4895-903.

37. Crofford LJ, Pillemer SR, Kalogeras KT, et al. Hypothalamic-pituitaryadrenal axis perturbations in patients with fibromyalgia. Arthritis Rheum 1994;37:1583-92.

38. Heim C, Ehlert U, Hanker J, Hellhammer DH. Abuse-related posttraumatic stress disorder and alterations of the hypothalamo-pituitary adrenal axis in women with chronic pelvic pain. Psychosom Med (in press).

39. Poteliakhoff A. Adrenocortical activity and some clinical findings in acute and chronic fatigue. J Psychosom Res 1981;25:91-5.

40. Ur E, White PD, Grossman A. Hypothesis: cytokines may be activated to cause depressive illness and chronic fatigue syndrome. Eur Arch Psychiatry Clin Neurosci 1992;241:317-22.

41. Buske-Kirschbaum A, Jobst $S$, Psych $D$, et al. Attenuated free cortisol response to psychosocial stress in children with atopic dermatitis. Psychosom Med 1997;59:419-26.

42. Yehuda R, Giller EL, Southwick SM, Lowy MT, Mason JW. Hypothalamic-pituitary-adrenal dysfunction in posttraumatic stress disorder. Biol Psychiatry 1991;30:1031-48

43. Yehuda R, Teicher MH, Trestman RL, Levengood RA, Siever LJ. Cor tisol regulation in posttraumatic stress disorder and major depression: a chronobiological analysis. Biol Psychiatry 1996;40:79-88

44. Schulkin J, McEwen BS, Gold PW. Allostasis, amygdala, and anticipatory angst. Neurosci Biobehav Rev 1994;18:385-96.

45. Schulz P, Kirschbaum C, Pruessner J, Hellhammer DH. Increased free cortisol secretion after wakening in chronically-stressed individuals due to work overload. Stress Med (in press).

46. Baum $\mathrm{A}$, Cohen $\mathrm{L}$, Hall $\mathrm{M}$. Control and intrusive memories as possible determinants of chronic stress. Psychosom Med 1993;55:274-86. 47. Brindley DN, Rolland Y. Possible connections between stress, diabetes, obesity, hypertension and altered lipoprotein metabolism that may result in atherosclerosis. Clin Sci 1989;77:453-61.

48. Verdecchia P, Schillaci G, Borgioni C, et al. Cigarette smoking, ambu latory blood pressure and cardiac hypertrophy in essential hypertension. J Hypertens 1995;13:1209-15.

49. Bernadet P. Benefits of physical activity in the prevention of cardiovascular diseases. J Cardiovasc Pharmacol 1995;25:Suppl 1:S3-S8.

50. Manuck SB, Kaplan JR, Adams MR, Clarkson TB. Studies of psychosocial influences on coronary artery atherogenesis in cynomolgus monkeys. Health Psychol 1988;7:113-24

51. Shively CA, Clarkson TB. Social status and coronary artery atheroscle rosis in female monkeys. Arterioscler Thromb 1994;14:721-6.

52. Bosma $\mathrm{H}$, Marmot MG, Hemingway $\mathrm{H}$, Nicholson AC, Brunner E, Stansfeld SA. Low job control and risk of coronary heart disease in White hall II (prospective cohort) study. BMJ 1997;314:558-65.

53. Schnall PL, Schwartz JE, Landsbergis PA, Warren K, Pickering TG. Relation between job strain, alcohol, and ambulatory blood pressure. Hypertension 1992;19:488-94

54. Everson SA, Lynch JW, Chesney MA, et al. Interaction of workplace demands and cardiovascular reactivity in progression of carotid atherosclerosis: population based study. BMJ 1997;314:553-8.

55. Raikkonen K, Lassila R, Keltikangas-Jarvinen L, Hautanen A. Association of chronic stress with plasminogen activator inhibitor-l in healthy middle-aged men. Arterioscler Thromb Vasc Biol 1996;16:363-7.

56. Markowe HLJ, Marmot MG, Shipley MJ, et al. Fibrinogen: a possible link between social class and coronary heart disease. BMJ 1985;291:1312 4.

57. Seeman TE, Singer BH, Rowe JW, Horwitz RI, McEwen BS. Price of adaptation - allostatic load and its health consequences: MacArthur studies of successful aging. Arch Intern Med 1997;157:2259-68.

58. McEwen BS, De Kloet ER, Rostene W. Adrenal steroid receptors and actions in the nervous system. Physiol Rev 1986;66:1121-88.

59. Eichenbaum H, Otto T, Cohen NJ. The hippocampus - what does it do? Behav Neural Biol 1992;57:2-36.

60. LeDoux JE. In search of an emotional system in the brain: leaping from fear to emotion and consciousness. In: Gazzaniga M, ed. The cognitive neurosciences. Cambridge, Mass.: MIT Press, 1995:1049-61.

61. Pugh CR, Tremblay D, Fleshner M, Rudy JW. A selective role for corticosterone in contextual-fear conditioning. Behav Neurosci 1997;111:503 11 .

62. Sapolsky RM. Stress in the wild. Sci Am 1990;262:116-23.

63. Jacobson L, Sapolsky R. The role of the hippocampus in feedback regulation of the hypothalamic-pituitary-adrenocortical axis. Endocr Rev 1991;12:118-34

64. Herman JP, Cullinan WE. Neurocircuitry of stress: central control of 
the hypothalamo-pituitary-adrenocortical axis. Trends Neurosci 1997;20: 78-84

65. Kirschbaum C, Wolf OT, May M, Wippich W, Hellhammer DH Stress- and treatment-induced elevations of cortisol levels associated with impaired declarative memory in healthy adults. Life Sci 1996;58:1475-83. 66. McEwen BS, Sapolsky RM. Stress and cognitive function. Curr Opin Neurobiol 1995;5:205-16.

67. Lupien SJ, McEwen BS. The acute effects of corticosteroids on cognition: integration of animal and human model studies. Brain Res Brain Res Rev 1997;24:1-27.

68. McEwen BS, Albeck D, Cameron H, et al. Stress and the brain: a paradoxical role for adrenal steroids. Vitam Horm 1995;51:371-402.

69. Uno H, Tarara R, Else JG, Suleman MA, Sapolsky RM. Hippocampal damage associated with prolonged and fatal stress in primates. J Neurosci 1989;9:1705-11.

70. Sapolsky RM. Why stress is bad for your brain. Science 1996;273:74950.

71. McEwen BS, Magarinos AM. Stress effects on morphology and function of the hippocampus. Ann N Y Acad Sci 1997;821:271-84

72. Kerr DS, Campbell LW, Applegate MD, Brodish A, Landfield PW.

Chronic stress-induced acceleration of electrophysiologic and morphometric biomarkers of hippocampal aging. J Neurosci 1991;11:1316-24.

73. Kerr DS, Campbell LW, Thibault O, Landfield PW. Hippocampal glucocorticoid receptor activation enhances voltage-dependent $\mathrm{Ca} 2+$ conductances: relevance to brain aging. Proc Natl Acad Sci U S A 1992;89:852731.

74. Choi DW. Calcium-mediated neurotoxicity: relationship to specific channel types and role in ischemic damage. Trends Neurosci 1988;11:465-

75. Mills LR, Kater SB. Neuron-specific and state-specific differences in calcium homeostasis regulate the generation and degeneration of neuronal architecture. Neuron 1990;4:149-63.

76. Mattson MP. Calcium as sculptor and destroyer of neural circuitry. Exp Gerontol 1992;27:29-49.

77. Meaney MJ, Tannenbaum B, Francis D, et al. Early environmental programming; hypothalamic-pituitary-adrenal responses to stress. Semin Neurosci 1994;6:247-59.

78. McEwen BS, Biron CA, Brunson KW, et al. The role of adrenocorticoids as modulators of immune function in health and disease: neural, endocrine and immune interactions. Brain Res Brain Res Rev 1997;23:79113

79. Dhabhar FS, Miller AH, Stein M, McEwen BS, Spencer RL. Diurnal and acute stress-induced changes in distribution of peripheral blood leukocyte subpopulations. Brain Behav Immun 1994;8:66-79.

80. Dhabhar FS, Miller AH, McEwen BS, Spencer RL. Effects of stress on immune cell distribution: dynamics and hormonal mechanisms. J Immunol 1995; 154:5511-27.

81. Miller AH, Spencer RL, Hassett J, et al. Effects of selective type I and II adrenal steroid agonists on immune cell distribution. Endocrinology 1994; $135: 1934-44$

82. Herbert TB, Cohen S. Stress and immunity in humans: a meta-analytic review. Psychosom Med 1993;55:364-79

83. Dhabhar FS. Stress-induced enhancement of antigen-specific cellmediated immunity: the role of hormones and leukocyte trafficking. New York: Rockefeller University, 1996.

84. Dhabhar FS, McEwen BS. Stress-induced enhancement of antigen-specific cell-mediated immunity. J Immunol 1996;156:2608-15.

85. Dhabhar FS, Miller AH, McEwen BS, Spencer RL. Stress-induced

changes in blood leukocyte distribution: role of adrenal steroid hormones. J Immunol 1996;157:1638-44.

86. Dhabhar FS, McEwen BS. Moderate stress enhances, and chronic stress suppresses, cell-mediated immunity in vivo. Soc Neurosci 1996;22:1350. abstract.

87. Cohen S, Tyrrell DAJ, Smith AP. Psychological stress and susceptibility to the common cold. N Engl J Med 1991;325:606-12.

88. Hadid R, Spinedi E, Giovambattista A, Chautard T, Gaillard RC. Decreased hypothalamo-pituitary-adrenal axis response to neuroendocrine challenge under repeated endotoxemia. Neuroimmunomodulation 1996;3: 62-8.

89. Taylor SE, Repetti RL, Seeman T. Health psychology: what is an un healthy environment and how does it get under the skin? Annu Rev Psychol 1997;48:411-47.

90. Lynch JW, Kaplan GA, Cohen RD, Tuomilehto J, Salonen JT. Do cardiovascular risk factors explain the relation between socioeconomic status, risk of all-cause mortality, cardiovascular mortality, and acute myocardial infarction? Am J Epidemiol 1996;144:934-42.

91. Marmot MG, Smith GD, Stansfeld S, et al. Health inequalities among British civil servants: the Whitehall II study. Lancet 1991;337:1387-93.

92. Pickering TG, Devereux RB, James GD, et al. Environmental influenc es on blood pressure and the role of job strain. J Hypertens Suppl 1996; 14:S179-S185.

93. Melin B, Lundberg U, Soderlund J, Granqvist M. Psychological and physiological stress reactions of male and female assembly workers: a com parison between two different forms of work organization. J Organizat

Psychol (in press).

94. Bobak M, Marmot M. East-West mortality divide and its potential ex planations: proposed research agenda. BMJ 1996;312:421-5.

95. Larsson B, Seidell J, Svardsudd K, et al. Obesity, adipose tissue distribution and health in men - the study of men born in 1913. Appetite $1989 ; 13: 37-44$

96. Brunner EJ. The social and biological basis of cardiovascular disease in office workers. In: Blane D, Brunner EJ, Wilkinson RG, eds. Health and social organization. London: Routledge, 1996:272-313.

97. Cohen S, Kaplan JR, Cunnick JE, Manuck SB, Rabin BS. Chronic social stress, affiliation and cellular immune response in nonhuman primates. Psychol Sci 1992;3:301-4

98. Cohen S, Doyle WJ, Skoner DP, Rabin BS, Gwaltney JM Jr. Social ties and susceptibility to the common cold. JAMA 1997;277:1940-4.

99. Redelmeier DA, Rozin P, Kahneman D. Understanding patients' decisions: cognitive and emotional perspectives. JAMA 1993;270:72-6.

100. Horwitz RI, Horwitz SM. Adherence to treatment and health outcomes. Arch Intern Med 1993;153:1863-8.

101. Seeman TE, McEwen BS. The impact of social environment characteristics on neuroendocrine regulation. Psychosom Med 1996;58:459 71 .

102. Spiegel D, Bloom JR, Kraemer HC, Gottheil E. Effect of psychosocial treatment on survival of patients with metastatic breast cancer. Lancet 1989;2:888-91.

103. Richardson JL, Shelton DR, Krailo M, Levine AM. The effect of compliance with treatment on survival among patients with hematologic malignancies. J Clin Oncol 1990;8:356-64.

104. Fawzy FI, Fawzy NW, Hyun CS, et al. Malignant melanoma: effects of an early structured psychiatric intervention, coping, and affective state on recurrence and survival 6 years later. Arch Gen Psychiatry 1993;50:6819.

105. Stern Y, Alexander GE, Prohovnik I, et al. Relationship between lifetime occupation and parietal flow: implications for a reserve against Alzheimer's disease pathology. Neurology 1995;45:55-60.

106. Stern Y, Alexander GE, Prohovnik I, Mayeux R. Inverse relationship between education and parietotemporal perfusion deficit in Alzheimer's disease. Ann Neurol 1992;32:371-5

107. Van Cauter E, Leproult R, Kupfer DJ. Effects of gender and age on the levels and circadian rhythmicity of plasma cortisol. J Clin Endocrinol Metab 1996;81:2468-73.

108. Handa RJ, Nunley KM, Lorens SA, Louie JP, McGivern RF, Bollnow MR. Androgen regulation of adrenocorticotropin and corticosterone secretion in the male rat following novelty and foot shock stressors. Physiol Behav 1994;55:117-24.

109. Juraska JM, Fitch JM, Henderson C, Rivers N. Sex differences in the dendritic branching of dentate granule cells following differential experience. Brain Res 1985;333:73-80.

110. Gould E, Westlind-Danielsson A, Frankfurt M, McEwen BS. Sex differences and thyroid hormone sensitivity of hippocampal pyramidal cells. J Neurosci 1990;10:996-1003.

111. Roof RL. The dentate gyrus is sexually dimorphic in prepubescent rats: testosterone plays a significant role. Brain Res 1993;610:148-51.

112. Kimura D. Sex differences in the brain. Sci Am 1992;267:118-25.

113. Mizoguchi K, Kunishita T, Chui DH, Tabira T. Stress induces neuronal death in the hippocampus of castrated rats. Neurosci Lett 1992;138: $157-60$. 